Revista Iberoamericana, Vol. LXXII, Núms. 215-216, Abril-Septiembre 2006, 497-514

\title{
ADORNO Y BENJAMIN SOBRE LA CULTURA: ACERCA DE UN EQUÍVOCO PERSISTENTE
}

\author{
POR \\ Roberto A. Follari \\ Universidad Nacional de Cuyo
}

Beatriz Sarlo es una autora apocalíptica que critica a la TV, es una opinión generalizada entre el alumnado de la carrera de Ciencias de la Comunicación. Los estudiantes han asumido un "nuevo sentido común” por el cual cualquier crítica dirigida a los medios es inmediatamente tachada de “apocalíptica”, y con dicho rótulo, descalificada in toto como parte de una supuestamente superada noción propia de criterios ideologistas y anticuados. Si no fuera que en sentido estricto es imposible hablar de paradigmas en las ciencias sociales (Follari, “Sobre la inexistencia” 111), se diría que el paradigma impuesto en la Comunicología latinoamericana es aquel que propone: 1. Que los medios masivos -en especial la televisión- carecen de poder de influencia propio destacable; 2. que quienes miran TV tienen una alta capacidad para poder discernir acerca de los significados a disposición; 3. que incluso ello los lleva a establecer tácticas de resistencia cultural, política e ideológica, y 4. que no viene a cuento nunca el mote de “integrados” que pudiera aplicarse a autores que hablan elogiosamente sobre los medios, pero sí cabe apostrofar a quienes se propongan criticarlos.

La impregnación de esta concepción se ha hecho tan significativa y naturalizada que los estudiantes no entienden que para el resto de las ciencias sociales la advertencia del peso de los medios sobre la opinión pública sea cada vez más fuerte (Bourdieu; Sartori), y lo sea en un sentido crítico a menudo ácido. O en todo caso, cuando desde la Comunicación se reconoce esta situación, se lo hace con una desdeñosa asunción de que tales críticas surgen promovidas por una noción mecánica, que los estudiantes de Comunicación achacan a la ¿teoría? de la aguja hipodérmica, según la cual la influencia de los medios carecía de mediación alguna por la subjetividad del receptor. A partir de allí, el nuevo sentido común se siente por completo consolidado, y por ello tiende a pensar como una "anomalía" -una especie de error incomprensible- lo que esté en colisión con él (exactamente como Kuhn lo señala para aquello que no se configure de acuerdo al paradigma) (Kuhn; Pérez Rasanz).

De tal manera, ha quedado obturada cualquier mirada crítica sobre los medios -la televisión ante todo-, exactamente cuando la carnavalización de estos se manifiesta con más fuerza, cuando la subordinación a la tiranía del rating y el mercado lleva a niveles muy grandes de banalización, cuando la centralización de la propiedad configura holdings a menudo diseminados por todo tipo de medios, cuando la proliferación de talk-shows, reality-shows y programas de chimentos sobre la vida privada de "las estrellas" gana 
terreno impunemente en el campo de la programación. ¿Habrá que celebrar esta verdadera invasión del campo televisivo por la gritería, el vértigo y -en los mejores casos- la segmentación informativa? Cierto que no todo en la TV se limita a este tipo de emisiones, pero cierto también que ellas conllevan la mayor cantidad de tiempo disponible, y que logran niveles de audiencia que aplastan a los programas que no apelan al sensacionalismo y el escándalo.

Es evidente que existe una tensión entre la TV “deseable” y la “realmente existente”, y alguien podría señalar que defiende a la primera y no a la segunda. Pero no es este el sentido común hoy impuesto: los estudiantes defienden a la TV en tanto tal, como formadora de la cultura de masas. Si esta última debe ser defendida como empírica asunción de lo que la población efectivamente acepta, también debe aceptarse la acción de los medios que lleva a establecerla.

En un libro que alcanzó considerable difusión en Argentina, Oscar Landi planteaba una singular “teoría de la recepción” según la cual quien ve TV mantiene una conciencia lúcida a partir de la cual está en condiciones de tomar distancia de los mensajes y elegir sólo aquellos que se ajustan a su propia expectativa, surgida de condiciones culturales específicas (Devórame 70). El optimismo de Landi y su retorno a una idea de sujeto epistémico transparente -una noción que no es válida para referirse al estamento de los científicos, y menos aún puede serlo para quienes ven TV desde una "atención flotante"es expuesto en el libro de una forma siempre más matizada que las versiones que han tomado cuerpo en el estudiantado, las cuales son por su parte considerablemente maniqueas y a menudo desinformadas.

Una versión con más peso latinoamericano que la de Landi, es la propuesta por J. Martín-Barbero en De los medios a las mediaciones, anterior cronológicamente a la de Landi. Su libro publicado a mediados de los ochentas proponía la acentuación de lo cultural como el punto decisivo para comprender las modalidades de interpretación que se haga de los medios. Lo hacía, sin embargo, con algunas diferencias respecto de Landi: la posición político-ideológica resultaba más combativa con respecto al capitalismo, por una parte. Por la otra, la densidad en el análisis de las culturas populares latinoamericanas referidas a los iniciales tiempos de expansión de la radio en la primera mitad del siglo xx, dejaban espacio a una versión no del todo consagratoria de la posterior cultura de masas propuesta por la televisión.

Una primera lectura de Barbero podría ponerlo definidamente en la tradición de Mariátegui, en la capacidad del peruano para comentar el turf o las costumbres cotidianas, y así repolitizar la interpretación de estos espacios, habitualmente dejados de lado por los análisis economicistas de la izquierda hegemónica. Sin embargo, la lectura que los estudiantes han hecho ha sido inversa. Se ha despolitizado el análisis de estos objetos de lo cotidiano y lo popular en sí mismos, a la vez que se ha desconectado de toda referencia a la política en su sentido más específico. De tal manera que se ha “puesto del revés” el significado inicial del texto, resemantizándolo en la dirección de un sentido común descomprometido y acrítico. Sin duda que es esta una clave en que puede leerse la obra de Martín-Barbero, que abriera fuertemente campo hacia los posteriores desarrollos de los estudios sobre comunicación en Latinoamérica. Ante la idea de la industria cultural como totalización de la significación en manos del sistema, el mercado y la trivialización, 
ninguna posibilidad política surge, que no sea la de la negación puramente ética, o la de la integración a partir de la imposibilidad de oponerse. Señalar que existen interpretaciones divergentes, que estas dependen de la condición cultural del receptor, que éste no queda convencido necesariamente por lo que los medios presenten, deja abierto el espacio a la posibilidad de la acción y la resistencia.

Pero no es precisamente ésta la lectura mayoritaria que se ha hecho de la obra, en sus consecuencias hacia la constitución de una "cultura cotidiana" del estudiantado. Por el contrario, se ha llegado a entender que en realidad es innecesario criticar a los medios, pues estos no influyen demasiado a nadie; los receptores tendrían tan amplia libertad interpretativa, que sería casi indiferente cuál es el tipo de mensaje que reciben. Se volvería tan ociosa como odiosa cualquier crítica a los medios, pues supondría agentes ideologizados (y por tanto anacrónicos), que expresan por esa vía su resentimiento de intelectuales contra la cultura de masas. Y la lectura política debiera ser denegada, pues la gente no va a encontrar política en los medios, sino a satisfacer sus deseos de esparcimiento y diversión.

¿Cómo es que ha podido producirse tal inversión de acentos en la interpretación del aporte de Jesús Martín-Barbero? Es en este sentido que se hace necesaria una teorización de cómo se dio la recepción de la “teoría de la recepción”. Ciencias de la comunicación es una carrera de moda en Latinoamérica desde mediados de la década de los ochentas. Por un lado, porque es una especialidad relativamente nueva. Por otro, porque el auge de uno de sus principales objetos de tratamiento (los medios masivos) ha conllevado el de la disciplina que lo estudia. Lo cierto es que se trata de una carrera con una muy amplia matrícula de ingreso, lo cual obviamente implica que este no es demasiado selectivo. A esto se suma que la expectativa del estudio sobre los medios es a menudo ella misma una expectativa mediática, no académica. Así como muchos alumnos de Ciencias Políticas (y ya no en su primer año de estudios) responden que estudian "para llegar a ser políticos" cuando se les pregunta por qué eligieron su carrera -confundiendo así la política como objeto de la ciencia con la política práctica-, los estudiantes de Comunicología a menudo estudian esa carrera porque quieren ocupar lugares en los medios, sin tener en cuenta una expectativa propiamente académica al respecto. La corta tradición científica de la disciplina coadyuva para que el equívoco se incremente. Pero por cierto que toda generalización puede pecar de error o unilateralidad. Sin duda existen no pocos estudiantes de la carrera que no quieren ser comunicólogos sino comunicadores, y que por ello ven en los medios un espacio de desempeño profesional, además de -en algunos casos- un lugar posible de consagración, incluso de salto a la fama o el estrellato. Es por ello que estos alumnos asumen como interés propio el que los medios salgan bien parados, fuera de cualquier crítica. El fuerte deslizamiento de sentido operado en la interpretación de la obra de Martín-Barbero hace que muchos de estos no-lectores de su obra (es obvio que la mayoría no la conoce de primera mano), terminen recitando su propio discurso autojustificante, antes que haciendo una versión plausible de lo establecido por el escritor de origen español. Este tipo de estudiante no tiene intereses expresamente políticos, sino personales, profesionales y económicos. De tal modo, la dimensión de acción política crítica que pueda extraerse del texto les está por completo fuera del horizonte de inteligibilidad, y lo que destacan-como en toda lectura ocurre-es sólo aquello que se hace compatible con sus personales inclinaciones y deseos. 
Es por ello que han banalizado el análisis de una cuestión tan decisiva hoy como es la de la influencia mediática, donde se juega uno de los lugares troncales para la configuración de opinión pública en los difíciles momentos que atraviesa Latinoamérica. Su versión de la "teoría de la aguja hipodérmica” resulta caricaturesca, ya que es obvio que jamás pudo creerse que todo lo que emitieran los medios se asumía por los receptores: de lo contrario, estos fumarían diez marcas diferentes de cigarrillos, o comprarían automóviles que no necesitan. También se hace poco relevante señalar que la recepción es activa, pues ya desde la añeja escuela de la Gestalt se sabe que la percepción es una construcción, y que su gramática se establece a partir de la necesaria selección y reconfiguración de los estímulos exteriores. De modo que la cuestión es más bien determinar qué efectos se producen en el sujeto (o en su caso, en un grupo social o una unidad cultural determinada) a partir de los estímulos auditivos, o los visuales que se recibe por los medios masivos. Allí comienza la discusión relevante acerca de la constitución del significado, y también -por otro lado- de los efectos sobre la configuración de la subjetividad (González Requena).

Sobre el significado desde el punto de vista de la cultura, y de las relaciones de ésta con la política, trata aquel libro inicial de Martín-Barbero. Con una lejana referencia a esa obra, a través de otras más despolitizadas, como la de Landi, los estudiantes han ido haciendo su propia “novela familiar” (Freud dixit) que ha terminado en la aceptación lisa y llana de la realidad como si esta tuviera en sí misma la justificación de su existencia. Un conformismo distraído al que Morley ha señalado con molde irónico: se trata de un "Don't worry, be happy”, isomórfico con alguna publicidad en boga (Morley, Televisión).

Y por cierto: ¿qué tendría que ver Walter Benjamin con todo esto? Aparentemente nada, dado que su escritura parece estar muy lejos de una polémica como la que estamos refiriendo. Sin embargo, los estudiantes de Comunicación explícitamente lo señalan como una de sus fuentes de legitimación discursiva. Benjamin habría sido un defensor inequívoco de la cultura de masas (sin tener en cuenta, por cierto, que ésta no incluía aún a la TV cuando él se suicida en 1940), alguien que se alejaba de los privilegios de la cultura letrada y el saber de los intelectuales. Es más: no tendría rasgo alguno de relación con nociones revolucionario-marxistas en lo político, ni tampoco con la “elitista” Escuela de Frankfurt, apostrofada en bloque a partir de la conocida postura de Adorno sobre el jazz (Lunn 181). Tan sorprendente referencia al escritor alemán -por cierto, menos leído aún que MartínBarbero por los estudiantes de Comunicología-, reconoce también alguna huella deformada en relación con la exposición del autor español radicado en Latinoamérica. El ha propuesto la influencia de Benjamin como decisiva en la configuración de su propia escritura (Martín-Barbero “Mis encuentros” 16), de manera que aquellos que han tomado partido a favor de la cultura masiva entienden que esta mediación puede autorizar la referencia a la autoridad de un autor del peso de Benjamin para sostener sus propias posiciones. "Más que sus temas, lo que me aportó Benjamin fue la disolución del centro como método”, sugiere Martín-Barbero, para puntualizar cuál fue la influencia recibida ("Mis encuentros” 19). 
BEATRIZ SARLO: POPULISMO y ELITISMO REVISITADOS

Cabe aquí entroncar con una posición radicalmente opuesta dentro de los estudios culturales latinoamericanos en general, y sobre la valoración de los medios y la cultura masiva en especial, como es la de la argentina Beatriz Sarlo. Tiene en común con el conjunto de los “estudios culturales” el remitir a la dimensión cultural como centro predominante de atención: las ciencias sociales están casi ausentes en sus análisis, o son presentadas a partir del criterio predominantemente estético (tal sucede con sus referencias a Bourdieu). En su caso, el estatus concedido a la cultura letrada la lleva a dar un peso mayor a la "alta cultura", los aparatos especializados de política cultural, y el campo literario, por encima de -o excluyendo de plano- la referencia a la cultura de masas: los deportes, los medios masivos, la historieta.

Sarlo rechaza de plano el conformismo político supuesto en un tratamiento acrítico de la televisión y el conjunto de las nuevas tecnologías de la información y el ocio (videojuegos, por ej.). Destaca con fuerza cómo el peso de los expertos y los críticos ha sido reemplazado por un simulacro de democracia, tal cual es el “libre” juego del mercado:

Me refiero a la salida de emergencia descubierta por el populismo cultural, que encuentra en los síntomas del mercado un reemplazo capitalista a la vieja noción romántica de Pueblo. Para utilizar sin sobresaltos la salida de emergencia que señala el neo-populismo de mercado, hay que hacer ojos ciegos frente a algunas cuestiones. La primera es la de su ley de hierro: el lucro... ("El relativismo absoluto” 30)

También destaca Sarlo que la "libertad” de quien interpreta los discursos e imágenes televisivas no es tal, en tanto lo hace de acuerdo a sus competencias intelectuales adquiridas, y muchas de éstas han sido establecidas por la televisión misma, con lo cual se compone un círculo vicioso sin salidas (“Estética y política” 58).

El ataque realizado por la autora contra la aceptación indiscriminada de la cultura de masas es contundente cuando se remite a los efectos ideológicos integradores que tal aceptación promueve:

\footnotetext{
afirmar que un receptor popular o de elite de la industria cultural no es sólo manipulado por el mensaje sino que puede a su vez manipularlo, no implica afirmar que con un mensaje cualquiera puede hacer prácticamente cualquier cosa...Incluso invertir su sentido, como en el caso de la parodia, supone una actividad extremadamente compleja y encuentra en el mensaje puntos que lo hacen posible y puntos que lo impiden. ("Lo popular” 24)
}

También, en su enfrentamiento al relativismo estético, Sarlo señala: “Nadie podrá ser condenado por sus ideas estéticas, pero nadie tendrá los instrumentos que permita hacer que las diferentes estéticas puedan compararse, discutirse y validarse. El mercado, experto en equivalentes abstractos, recibe a este pluralismo estético como la ideología más afín a sus necesidades” (“El relativismo absoluto” 29). Este rechazo de lo convencional y de cierto populismo para el cual todo está igualmente autorizado, se realiza desde un lugar epistémico que destaca la cultura letrada, la modernidad y el valor de los expertos como 
indisputable y necesario. Si bien ello está pensado por Sarlo como parte de los valores de la izquierda ideológica, no cabe duda de que implica un elitismo marcado, desde el cual la cultura de masas se rechaza en bloque. Esta defensa de la modernidad (que a diferencia de Habermas, se sustenta más en el gusto estético refinado que en la noción filosófica de “razón”) deja afuera todo aquello que hace al más rico aporte que plantean los estudios culturales, y que por cierto ha realizado Martín-Barbero: la inclusión de los temas “plebeyos" en la agenda, la entrada a la academia de lo mínimo y lo no-artístico, el entendimiento de la cultura como cotidianeidad vivida en la cual los sectores populares consumen radio, historietas, telenovelas, publicidades. Sarlo, en cambio, entiende como problemático no sólo el concepto de "cultura de masas", sino también el de "cultura popular” (los cuales, por cierto, no son distinguidos entre sí por la tradición sajona). Lamenta que el concepto especializado de cultura ligado al arte haya sido reemplazado por una noción más antropológica y abarcadora, en tanto ello ha permitido entender igualmente a todo objeto como objeto cultural. Así, buscando rescatar a Raymond Williams fuera de la tradición actual en que lo instalan los estudios culturales hegemónicos, Sarlo sostiene: “Como sea, en sus análisis, Williams adjudicó siempre un lugar distinguido a los discursos estéticos e ideológicos de los intelectuales” (“Lo popular” 20).

Como se ve, se trata de una defensa de la peculiaridad de los intelectuales y de los expertos, frente al emparejamiento igualitario que propone la cultura de masas. Por tanto, también de una crítica hacia quienes -desde la defensa de lo masivo- cuestionan esa superioridad de lo letrado, y hacen eco conceptual de las nuevas tendencias hegemónicas en el campo de la industria cultural. La postura de Sarlo aparece inevitablemente como elitista, e implica una elíptica minusvaloración de la cultura cotidiana de los sectores sociales subordinados, la cual nunca ha estado informada por lo letrado, ni por la gran literatura, ni por valores estéticos sofisticados y especializados. La defensa que la autora practica de los “expertos” y su rechazo del relativismo, se hacen en nombre de una muy tradicional apelación a la superioridad de la cultura intelectualizada, apelación que carece de matices y/o contrapesos.

Un buen ejemplo resulta su artículo en torno al tema de lo moderno/posmoderno, que aparecen como un par de opuestos, sin advertencia teórica de su mutua relación de constitución (lo posmoderno como sobre-moderno) (Follari, "Posmodernidad"). Si bien al final del trabajo se plantean algunas de las perplejidades a que su reivindicación de lo moderno lleva -por ej., la defensa de la tecnología-, todo el peso de la autorreflexión está cargado exclusivamente hacia la modernidad: "No hay cuestión estética posmoderna", afirma categóricamente (“Un debate” 89), negando a la vez a Lyotard y Vattimo, e incluso a la evidencia de que la posmodernidad es una época estetizante por excelencia.

Este artículo es por demás demostrativo de un equívoco notorio en la posición de Sarlo: tiende a analizar la modernidad no como una época, ni tampoco como una condición, sino como una extensión de su propia experiencia personal. Así, afirma taxativamente: “el Moderno (para el caso un moderno de izquierda)... Está, en primer lugar, su vocación de ruptura con lo realmente existente: la modernidad es insatisfecha, y por eso son modernas las figuras del revolucionario y del reformista profundo" ("Un debate” 89). El artículo siguiente al de Sarlo en esa publicación, "Lo actual y la modernidad”, de Renato Ortiz, opera como una refutación del de la escritora argentina. No 
es que esto sea falso, pero sí que es definidamente incompleto: modernos han sido los dictadores, los propulsores de la derecha tecnocrática, las posiciones ideológicas “fuertes”, por cierto no sólo -y tampoco mayoritariamente- de izquierda. La modernidad crítica a que refiere Sarlo sin duda ha existido, pero es sólo una de las facetas de lo moderno, y por cierto que está lejos de haber sido la dominante. De tal manera, la reducción de la modernidad a la figura del crítico de izquierdas, o al esteta letrado, el militante y el bohemio, resulta considerablemente desenfocada en relación con la modernidad hegemónica, racionalizante y subordinadora de la dimensión estética, productivista, regimentadora y burocrática (en los términos de la crítica que le ha hecho la Escuela de Frankfurt inicialmente, y luego Foucault). De esta última Sarlo no da cuenta; es más, parece considerarla inexistente o irrelevante. La falta de suficiente mediación teórica en las oposiciones moderno/posmoderno, cultura letrada/cultura popular y expertos/legos, promueve el equívoco de una defensa cerrada y unilateral de los primeros componentes de cada par, que no deja espacios para la cultura oral o la reflexión sobre las costumbres, y que tacha sin matices al relativismo estético y la posmodernidad como condenables, sin poder asumir aquello que de necesidad hay para que se hayan establecido con vigencia, en tanto el surgimiento de lo posmoderno se da ante el agotamiento y fracaso de la modernidad (Follari, Modernidad).

Tampoco estas especificidades analíticas sobre los trabajos de Beatriz Sarlo son conocidas por el común de los estudiantes de Comunicación. Se puede entender muy bien ahora a qué se referían cuando hablaban de la supuestamente apocalíptica autora: a su descalificación de la TV y de la cultura de masas en general. La cual a menudo es defendida por ellos no en nombre de la noción de "cultura popular" -que tiene larga raigambre en el pensamiento crítico latinoamericano-, sino en la de la versión sajona, esa que sostiene que “popular” es aquello que es más consumido, simplemente lo que tiene más llegada. Lo curioso es que también para Sarlo, Benjamin es una fuente inspiradora. Abundan los artículos sobre la obra del alemán en la revista Punto de Vista, que la escritora argentina dirige. Es, sin duda, uno de los autores más referidos y estudiados en el conjunto de la producción de dicha revista. Es decir, que Benjamin está en manos de tirios y troyanos, y es apelado desde ambos lados de la polémica. Polémica tensada entre posiciones que se presentan como definidamente no conciliables, y opuestas entre sí.

BENJAMIN: LA LETRA ENTRE TENSIONES

Se sabe que no se puede hablar de un "Benjamin verdadero". Está claro que sobre cualquier vida y cualquier obra existen interpretaciones múltiples, y no es factible dar a una-y a esa sola-certificado de validez. De cualquier modo-y esto por cierto vale también para la discusión sobre la interpretación de mensajes televisivos- esto no significa que cualquier interpretación sea igualmente válida, o que pueda realizarse arbitrariamente. Aquellas que se practiquen deben buscar ser compatibles con la mayor cantidad posible de documentos, testimonios y textos, y deben guardar una lógica explicativa interna no contradictoria.

En todo caso, la formación fuertemente literaria de Benjamin es indiscutible, tal como la posterior influencia de Brecht y el marxismo por un lado, y Scholem y la teología judía 
por el otro. Esto da lugar a la rara conjunción que se produce en su pensamiento y que no es fácil sintetizar en una exposición breve: “En lugar de una síntesis teórica, las obras de Benjamin revelan una explosiva fecundación recíproca de corrientes intelectuales y experiencias históricas registradas como por un sismógrafo” (Lunn 200). Quien haya leído las “Tesis para una filosofía de la historia”, o cualquiera de las "Iluminaciones” de Benjamin no puede dejar de apreciar la dificultad de su estilo fragmentario y aforístico, la extrema complejidad de las referencias literarias e históricas presentes, y sobre todo el dejo teológico respecto de la sublimidad del instante, la escritura en la cual la redención y lo sagrado reaparecen en una versión arduamente laica:

en la representación de felicidad vibra inalienablemente la de redención. Y lo mismo ocurre con la representación de pasado, del cual hace la historia asunto suyo. El pasado lleva consigo un índice temporal mediante el cual queda remitido a la redención. Existe una cita secreta entre las generaciones que fueron y la nuestra. Y como a cada generación que vivió antes que nosotros, nos ha sido dada una flaca fuerza mesiánica sobre la que el pasado exige derechos. (“Tesis” 178)

¿Puede la sensibilidad de Benjamin tolerar los talk-shows al estilo “Cristina”, la locutora de Miami? ¿Es posible no advertir el abismo que separa esa escritura semi-mística de las comerciales tandas de música seudo-tropical que la mayoría de los canales de TV argentinos prodigan los sábados por la tarde?...El contraste no puede ser más rotundo. Sin embargo, el cuasi-paradigma de la Comunicología latinoamericana se sostiene en la supuesta certidumbre de que Benjamin fue un defensor decidido de la cultura de masas, y que la TV actual puede defenderse homogéneamente en su nombre. Y es esto lo que aparece como fuertemente inadecuado, una interpretación de Benjamin que opera de hecho contra gran parte de la letra y la vida del autor. Y es este un equívoco que es necesario disipar.

\section{SOBRE “LA OBRA DE ARTE EN LA ÉPOCA DE SU REPRODUCTIBILIDAD TÉCNICA”}

Este sería, a todas luces, el escrito a partir del cual se supone que la “desaparición del aura” autoriza a pensar que cualquier nueva tecnología mediática sería valorada positivamente por el autor alemán. No cabe duda que la direccionalidad del texto está influida por Brecht, y que tiende a pensar al cine como una opción de masas que permita vía, por ejemplo, el montaje, romper estereotipos ideológicos. La postura "favorable" hacia las posibilidades de la reproducción masiva del arte es ciertamente evidente. Pero esto, no sin especificaciones. Una primera cuestión es que en este caso se apunta principalmente al cine, no a la televisión. Alguien podría afirmar que si Benjamin hubiera vivido durante los tiempos televisivos, hubiera extendido allí sus reflexiones: pero tal postulación es contra-fáctica e indemostrable. De hecho, el cine es visto en lugares públicos y colectivamente, mientras la TV promueve una experiencia privatizada y de separación física respecto de lo ajeno al propio espacio familiar. Y la "atención flotante" que la TV permite, el hecho de interrumpir la visión, ocuparse de otras cuestiones, etc. (Landi, "Mirando") resulta muy diferente a la condición de continuidad que establece la sala cinematográfica, además de la oscuridad que en ella existe. Por lo tanto, el paso de 
la referencia al cine hacia el caso de la TV es menos obvio de lo que suele suponerse. En segundo lugar, el contenido a que apunta Benjamin no es cualquiera: piensa en filmes que promuevan el pensamiento. Da el ejemplo de Chaplin, y las referencias al montaje, más su admiración por el surrealismo, llevan a pensar en Buñuel. Es cierto que por momentos se plantea una aceptación del medio por sí mismo: "La vulnerabilidad del ensayo (aparte del hecho de que no había captado las realidades soviéticas en los años treinta) residía en su aparente insistencia en que todos estos cambios no eran tanto usos potenciales como implicaciones inherentes de los nuevos medios de comunicación”, señala Lunn. Pero de inmediato agrega: "Lo que impedía su realización inmediata, en su opinión, era la dialéctica de los modos productivos y las relaciones de producción en la sociedad capitalista...” (178).

Como se puede ver, dentro del capitalismo las potencialidades de la técnica estarían limitadas por las condiciones sociales. Mal podría -entonces- afirmarse que Benjamin sostiene que dentro del capitalismo la cultura efectivamente existente debe ser celebrada (en tanto guardaría inmanentemente potencialidades críticas). En todo caso, quizá quepa pensar en la radical ambivalencia de Benjamin sobre los procesos de la modernidad y el abandono de la tradición. Por una parte, el autor sostenía el valor de lo antiguo, incluso hablaba de su sentido "revolucionario": "No hay aquí cabida para el progresismo futurista, ya que la acción revolucionaria debe liberar el pasado oprimido. Con estas tesis, Benjamin combate la testaruda fe en el progreso de la socialdemocracia y el marxismo vulgar" (Aguirre 9). Y también refuta cualquier confianza lineal depositada sobre las nuevas tecnologías y sus posibilidades, se podría agregar. Es en este sentido que el texto sobre la reproductibilidad tiene que ponerse en relación con el conjunto de la obra de Benjamin para interpretarse. Y que en tal contexto, cualquier optimismo unilateral en la interpretación de la modernidad y la modernización, resulta poco fiel a la matizada toma de posición del escritor alemán: “En el caso de Benjamin, esto revelará la estudiada ambivalencia que muestra su obra en conjunto hacia la crisis de la cultura tradicional que Brecht había visto simplemente como una oportunidad esperanzadora” (Lunn 175).

Finalmente, cabe repetir la conocida cita del final del trabajo de Benjamin sobre la reproductibilidad técnica, para apreciar el horizonte de inteligibilidad en que se inscribía, lejos de cualquier celebración banal de los avances tecnológicos, y menos aún de la cultura de la distracción y el ocio: "La humanidad, que antaño, en Homero, era un objeto de espectáculo para los dioses olímpicos, se ha convertido ahora en espectáculo de sí misma. Su autoalienación ha alcanzado un grado que le permite vivir su propia destrucción como un goce estético de primer orden. Este es el esteticismo de la política que el fascismo propugna. El comunismo le contesta con la politización del arte” (“La obra” 57).

BENJAMin DEFIENDE LA CULTURA LETRADA

Por cierto, no hay en Benjamin denuestos contra la cultura callejera: por el contrario, su gusto por la deambulación y las colecciones, su búsqueda de objetos raros y viejos lo muestran como alguien capaz de tener los ojos abiertos más allá del campo de lo letrado. Pero sin dudas, Benjamin lee lo no-letrado desde lo letrado. Dicho de otro modo, propone y sostiene una sensibilidad estética sofisticada que sólo puede alcanzarse gracias a la 
lectura sistemática de los clásicos. La no-oposición entre ambos tipos de cultura, puede establecerse sólo a partir de que la una reconozca la existencia de la otra.

Es entendible entonces que la sola cultura de masas librada a su impulso inherente no produciría los efectos que la interpretación benjaminiana puede promover sobre los objetos en que repara. Los comentarios tan eruditos como exquisitos sobre Proust, Gide o el surrealismo (Imaginación) muestran una riqueza de matices y sutileza de comentarios, que sólo pueden surgir del detalle de quien hace de la lectura una necesidad asumida, no sólo por él personalmente, sino como modo "socialmente recomendable" de relacionarse con el mundo. Véase, si no, la arrobada reflexión de Benjamin en torno a su propia biblioteca, al gusto por los libros, tanto el tenerlos como objeto (lo cual, él señala, trasciende su lectura), como por lo que anticipan y guardan de la posibilidad de lectura misma. El goce casi fetichista que el artículo sobre el tema presenta, nos exime de comentarios respecto a un Benjamin supuestamente objetor de los indeseables "privilegios" asignados -según posiciones populistas- a la escritura (“Desembalo” 23).

BenJamin ES UN AUTOR DE LO SUBLIME

La teología judaica propuso a Benjamin su idea del nombrar como un modo de recrear las cosas. El lenguaje tendría una función cuasi-sagrada de constitución de mundos. A partir de allí, Benjamin está a años luz de celebrar cualesquiera formas de desencantamiento del mundo, como algunos han entendido por su posición sobre la "declinación del aura”. La influencia de Scholem en la obra y vida de Benjamin es suficientemente conocida, así como sus propios textos muestran lo antedicho (la cita ya transcripta habla de lo “mesiánico”, y dos veces de “redención”). Incluso sus varios escritos acerca de la droga pueden entenderse en este contexto de "experiencias de los límites".

También en este caso la fina trama de referencias aparecidas en los artículos sobre Proust o Gide, muestran el rescate del fragmento y el acontecimiento desde un punto de vista que a su vez no desdeña la dialéctica ni la comprensión histórica. Si bien el conocimiento filosófico de Benjamin era limitado, la búsqueda de mostrar "resonancias” entre lo material y el mundo del arte se sostuvo siempre (es un punto que está en el centro de su polémica con Adorno en torno a Baudelaire).

BENJAMIN NO ERA UN PENSADOR OPTIMISTA

La melancolía personal del escritor alemán se deja traslucir en muchos de sus textos, pero es además evidente en su biografía. Antes de su suicidio, ya había tenido otro intento. Benjamin no es un autor deconstruccionista avant la lettre o un propulsor del “desvanecimiento del ser” (Ballent et al. 20), pero es indudable que tuvo una personalidad inestable y depresiva, y que su obra expresó ese talante muy claramente. No puede sin violencia considerarse a Benjamin un defensor optimista del avance histórico que pudieran guardar las tecnologías, ni siquiera -en grado puro- del que pudiera conllevar la historia social de la humanidad. La cultura de masas, atravesada por el peso del consumo como uno de sus baluartes constitutivos (García-Canclini Consumidores), necesita 
mostrar la vida como alegre fiesta de las posibilidades de compra, y del deleite que estas posibilitarían. En esa tesitura, su grado de banalidad y trivialización llega muy a menudo a ser extremo. Entre el "tono psicológico" sombrío del ensayista germano, y el mundo de forzada algarabía del consumo propugnado por la TV, media el abismo más absoluto.

\section{BENJAMIN NO ERA UN PENSADOR LIGHT}

La cultura de masas, tal como la TV la propone, aparece hoy transida por la falsa alegría de un presente perpetuo, dentro del cual no caben el ensimismamiento, el silencio ni la reflexión. Ello conlleva la desaparición discursiva de la cuestión del sufrimiento, la cual es cuidadosamente ocultada, llevando suponer un mundo alivianado que niega los conflictos, el dolor y la muerte (Rojas y Sternbach). Esta versión posmodernizada de la subjetividad, está en las antípodas de las posiciones de Benjamin. Y en este sentido, se podría recordar a Vallejo: "Hay golpes en la vida tan fuertes, yo no sé...golpes como de la ira de Dios”. Y Benjamin, por su parte: “El surrealismo se ha aproximado más y más a la respuesta comunista. Lo cual significa: pesimismo en toda la línea. Así es y plenamente” ("El surrealismo" 60).

De modo que la asociación del pensador alemán a lecturas posmodernas está muy lejos de resultar genuina. Al menos en cuanto a lo que la cuestión del "alivianamiento" refiere.

BENJAMIN ERA UN MARXISTA REVOLUCIONARIO

Es cierto que lo era de una muy especial manera, y que nunca fue un militante. Pero Benjamin fue marxista y lo fue hasta su muerte, y su muerte lo fue por ser marxista. De modo que difícilmente pueda esto ser dejado de lado en el análisis. Si bien Martín-Barbero se reclama del legado del autor de las "Iluminaciones", declara en otro contexto: "El cuestionamiento de la razón instrumental no atañe únicamente al modelo informacional, sino que pone al descubierto lo que tenía de horizonte epistemológico y político el ideologismo marxista”. Y luego agrega: "De otro lado, la cuestión trasnacional desbordará en los hechos y en la teoría la cuestión del imperialismo...” (“La comunicación” 59). El abandono del marxismo por la aproximación trans-disciplinar propia de los estudios culturales se hace allí visible, propuesta que ha dado lugar a críticas específicas (Follari "Relevo"). Se podría alegar consistentemente que han cambiado los tiempos, y ya la revolución no está en el horizonte como parecía estarlo en tiempos de Benjamin. Es lícita esa posición, pero ello no autoriza a dejar de señalar claramente la filiación diferencial del pensador de Frankfurt, ya que ésta fue constitutiva de su pensamiento, no casual ni secundaria. Por ejemplo, cuando dice: “...en cualquier acto revolucionario está viva una componente de ebriedad. Esta componente se identifica con la anárquica. Pero poner el acento exclusivamente sobre ella significaría posponer por completo la preparación metódica y disciplinaria de la revolución”... (“El surrealismo” 58, énfasis nuestro). Hablando del surrealismo, señala: "En tales movimientos hay siempre un instante en que la tensión original de la sociedad secreta tiene que explotar en la lucha profana por el poder y el dominio, o de lo contrario se transformará y se desmoronará como manifestación pública” (45). 
Benjamin fue un miembro de la Escuela de Frankfurt

Es cierto que fue un miembro heterodoxo y enormemente singular dentro de la Escuela. Que tanto en su escritura como en la relación institucional con el Instituto, permaneció siempre como un semi-marginal, a medias incluido y a medias fuera, con contratos episódicos y acercamientos no permanentes. Pero está claro que fue influido por otros miembros de la escuela, y que a su vez influyó en ellos. Y que su esteticismo no resulta en absoluto ajeno al tipo de preocupaciones de la mayoría de los autores de la escuela frankfurtiana. Desde esta perspectiva, se hace confusa la noción sostenida desde el sentido común instalado en el estudiantado de Comunicación, según la cual Benjamin fue un celebrante de la cultura de masas, y los frankfurtianos fueron definitivamente “elitistas” (en el conjunto de tales frankfurtianos, ellos no incluyen a Benjamin). Con esta afirmación no sólo se desteje la real asociación histórica entre Benjamin y el resto de los escritores de Frankfurt, sino que se asume con escandalosa liviandad un juicio por el cual todo el trabajo filosófico de la Escuela es desconsiderado, en nombre de una cuestión parcial como es la de su aristocratismo cultural.

Tal simplificación impide advertir el lugar de nociones como negatividad y criticidad, las cuales aparecen entonces simplemente como caprichos de intelectuales elitistas. A su vez, implica desconocer que la razón instrumental fue criticada decididamente por vez primera por los frankfurtianos. La riqueza de la obra de estos autores en su crítica de la razón como dominio ha desembocado a largo plazo en obras posteriores que le son tributarias, como en Foucault, o incluso en algunos de los desarrollos posmodernos (por ej., las referencias de Lyotard a Adorno). Tales sutilezas quedan fuera de la dupla de mutua exclusión -imaginada- entre los frankfurtianos y Benjamin.

Adorno no es la contracara de Benjamin

Esto se liga fuertemente a lo señalado en el punto anterior, y remite al título general del presente artículo. Es cierto que existieron considerables tensiones entre Adorno y Benjamin: Lunn las muestra con precisión en su detallado estudio (Lunn 173). Adorno cuestionó fuertemente las tesis del texto sobre la reproductibilidad de la obra de arte, además del estudio sobre Baudelaire (Adorno y Benjamin). Tanto Benjamin como Adorno eran hijos de hombres ricos, comerciantes exitosos. Quizá desde allí mismo se entiende su compartido rechazo frontal de lo convencional y del mundo burgués. Uno detestaba tanto como el otro el campo de lo operativo y lo pragmático. La fuerte diferencia entre ellos residía en el concepto de "mediación” adorniano, notoriamente extraído de Hegel, y que suponía la no aceptación de una especie de intuicionismo del instante, presente en Benjamin por vía de la influencia de la teología judía. A partir de allí es que Adorno no podía aceptar una versión favorable como la que su amigo se planteaba en torno a la reproductibilidad de las obras de arte. Por el contrario, su concepto de industria cultural condenaba en masa esos desarrollos, en tanto no los advertía capaces de promover conciencia crítica ni de producir una "negación” del mundo productivista y mercantil.

La crítica de Adorno es menos frágil de lo que suele suponerse, ya que si bien la cultura de masas puede proponer diversión y reconocimiento identitario, difícilmente 
pueda predisponer a una ruptura con la sensibilidad o el pensamiento dominante. Si bien el lenguaje aristocrático del autor hace que se lo entienda solamente en términos de elitismo, la objeción hace a uno de los puntos más decisivos de la discusión a sostener sobre los estudios culturales latinoamericanos. ¿No lleva la total desacralización a una imposibilidad de generar valores alternativos desde los cuales retar a lo existente?

En todo caso, si bien los dos amigos diferían sobre la literatura francesa (que tanto atrapaba a Benjamin) o sobre las vanguardias (en las que siempre confió Adorno), ambos pensadores guardaban una noción fuertemente rupturista de la experiencia estética. Aunque Benjamin creyera que ello podía lograrse también con simples objetos antiguos, los dos pensadores proponían la discontinuidad, el acto de extrañamiento, la no linealidad de la experiencia. En este sentido, aquello que gustaba a Benjamin tenía que ver con su posibilidad de suspender el transcurrir del tiempo (subjetivamente, por supuesto), o de retrotraer estímulos desde el pasado. Por cierto, algo muy distante de la propuesta más difundida en la emisión mediática. Y sin duda, muy cercano a la noción adorniana de promover negatividad, extrañamiento frente al mundo de lo dado.

De modo que si bien en Adorno la huella hegeliana está siempre presente, lo está también la de Benjamin, el gusto por el fragmento o la sentencia fulminante: "El todo es lo no verdadero”. Justamente Minima moralia, libro de breves relatos personales y afirmaciones relampagueantes, es claro testimonio de la influencia de Benjamin, no exclusivamente detectable en este libro sino también en otros. Y a esto apunta Altamirano cuando afirma: "Refiriéndose a Benjamin, Adorno escribió que aquel celebraba en Karl Kraus un rasgo de sí mismo. Mediante una ligera paráfrasis, la fórmula podría ser empleada para Adorno, quien en su Caracterización de Walter Benjamin celebra en el otro rasgos de su propia obra”. Y cita a Adorno: “Todas sus manifestaciones -dice, hablando de los trabajos de Benjamín-se encuentran a la misma distancia del punto central” (2) (esto se podría cotejar con aquello que Martín-Barbero subraya en su personal recepción de Benjamín). Y continúa el texto: "El ensayo -género preferido de Adorno- se rehúsa así a simular la unidad de un orden conceptual sin brechas -donde lo que es particular, específico, cualitativo resulte ahogado o suministre, simplemente, el ejemplo de una categoría general- y asume ostensiblemente su carácter fragmentario” (3).

Adorno y Benjamin, entonces. Tan polémicos entre sí como sólo pueden estarlo quienes pisan el mismo campo (es evidente que no se puede discutir con aquellos que no comparten el mismo foco de interés; se discute siempre en torno a algo que compromete a la vez a los interlocutores). Los avatares de la academia han promovido una oposición simple entre ellos, que es incapaz de advertir matices, claroscuros e influencias mutuas.

\section{Cuál Benjamin en Latinoamérica}

Martín-Barbero ha mostrado una especial perspicacia y sensibilidad para penetrar en el mundo de las culturas subalternas, desentrañar sus usos, consumos y costumbres, y ofrecer una detallada gama de descripciones y explicaciones a su respecto. Desde De los medios a las mediaciones abrió un espacio de intelección para fenómenos habitualmente silenciados por la cultura de elites y la cultura letrada, y alentó a que se mirara con otros ojos el detalle, la saga de las tradiciones en fuga, la terca identificación con su mundo de 
parte de los condenados de la tierra. Se trata de una operación teóricamente necesaria y políticamente decisiva, en la medida en que las izquierdas habitualmente no han sido capaces de penetrar el mundo cultural de los sectores subordinados, y que a menudo lo han despreciado o, aún valorándolo, no han tenido herramientas para comprenderlo. En la mejor tradición de ese marxismo engarzado en el análisis de lo cultural que fuera propio de Gramsci o de Mariátegui, Martín-Barbero inauguró un espacio donde hoy las posibilidades continúan (por cierto, no era evidente por entonces que el autor se hubiera alejado del marxismo).

Martín-Barbero relata su encuentro con la escritura de Benjamin, y su delectación por ésta: "Si hay amores a primera vista...eso fue lo que sentí" ("Mis encuentros” 17). Y sin duda que su gusto por el detalle, su atención a los acontecimientos, dejan notar la influencia del ensayista alemán. Sin embargo, la escritura de Barbero no es fragmentaria ni supone cortes súbitos en el fluir del tiempo: “contrario a Benjamin, en Martín-Barbero el narrador no muere, el tiempo histórico no ha desaparecido, la mediación...” (Colón 36).

Se puede afirmar que en Martín-Barbero la influencia benjaminiana existe -como también existe en Sarlo-, pero que está subordinada a un tipo de discursividad y de explicación que le da una continuidad conceptual que aquélla no tiene. Al ser la obra de Martín-Barbero tendiente a la no-clausura temática, sin duda que lo es en una medida mucho menos marcada que en los abruptos cortes de Benjamin, y su tipo de escritura concientemente dispersa y descentrada. Es así que se pueden detectar en Martín-Barbero otras fuentes también importantes en su formación, y que han reabsorbido en parte el legado de Benjamin. Por una parte ese marxismo inicial, que el autor español fue abandonando con el tiempo. Y posteriormente (y por cierto en buena medida como "reemplazo" de dicho marxismo, como ha propuesto Jameson) (“Conflictos” 100), los estudios culturales, de raíz sajona, a partir de la tradición que va de Raymond Williams a Stuart Hall, y luego a la “importación” estadounidense de la corriente (Mattelart y Neveu).

Martín-Barbero rechaza la denominación de “estudios culturales” por algunas de sus implicaciones: "Si el regreso de Benjamin al tiempo del Sur se produce desde los márgenes, desde el exterior de la academia, el que visita el espacio de nuestras ciudades parece más ligado al acelerado ritmo de las modas en la internacional académica y sus etiquetas de prestigio, como la de los estudios culturales" ("Mis encuentros" 23). Sin embargo, parece difícil negar su relación personal con tal tipo de estudios, aún desde la elemental perspectiva de su lugar en las recopilaciones temáticas del género (Moraña).

Algunas de las características de los cultural studies sin duda que forman parte del acervo del pensador radicado en Colombia, como cierto peso de las humanidades en detrimento de las ciencias sociales (propio de la tradición sajona al respecto) (Yúdice), bien que mucho mejor equilibrado que en el caso de los autores estadounidenses; la pérdida de influencia de la "política normativa” en el discurso (Ferguson y Golding 21), ligada al alejamiento del marxismo; la búsqueda de una siempre problemática inter o transdisciplinariedad; la insistencia en la importancia de los placeres en el consumo mediático, etc. (Morley “Ortodoxias” 221). ${ }^{1}$

\footnotetext{
${ }^{1}$ Morley critica la supuesta resistencia adscripta a los placeres del televidente. Por su parte, Schlesinger hace una crítica cordial pero directa a Martín-Barbero, sobre todo en relación al supuesto
} 
Los estudios culturales han llegado como una cierta influencia Norte/Sur (Yúdice 10), y si bien han sido resemantizados en Latinoamérica, tal condición de origen tipifica muchos de sus logros, pero también de sus limitaciones. No podemos sino hacernos eco de lo que señala Mabel Moraña: “¿Cómo restituir...la historización y la política a análisis que al relocalizarse en torno a la centralidad de la cultura parecen resolverse, con frecuencia, en el solaz del pensamiento débil, las aventuras del pastiche ideológico, o las trampas de la amnesia colectiva?” (Moraña 10). O como Hermann Herlinghaus encuentra refiriéndose ya al mismo Martín-Barbero, dentro de un cuidado artículo muy elogioso de su obra: “...una autoinspección etnológica de la modernidad se está articulando hoy desde distintas perspectivas críticas. Esta se está convirtiendo no pocas veces en obsesión retórica que modula el principio de una descolonización del pensamiento occidental desde sus propios territorios académicos. Ahí reside su fuerza, pero también sus límites” (11). En todo caso, Martín-Barbero le ha agregado a esta propuesta no sólo su imaginación y capacidad para captar las especificidades latinoamericanas, sino también la influencia de Benjamin. Integrada en un discurso cuyos cauces se dibujan desde otras riberas teóricas, ha perdido en el decurso los puntos más ligados a la “detención” teológica y a la idea de revolución, pero ha recuperado su poder de iluminación en relación a conceptos más generales, y mantenido su capacidad para captar lo instantáneo y la minucia cotidiana, en la cual los sujetos sociales viven y se representan su drama.

Beatriz Sarlo, por su parte, ha retomado “el otro" Benjamin: el del arte excelso, el de la mística laica pero cuasi-teológica, el de las lecturas apasionadas de los grandes autores. Desde allí sostiene la importancia de la cultura letrada en la constitución cultural y en la resistencia política. Personalmente, se podría acordar con ambos objetivos, pero sin duda se trata en Sarlo de un Benjamin donde se ha perdido la capacidad para iluminar lo cotidiano, exactamente aquello que de él ha sabido destilar Martín-Barbero.

¿Cuál es hoy el valor de este autor de la primera mitad del siglo xx y tan singularmente bifronte, cuyas ambivalencias permiten tomarlo desde polos contrarios sin traicionarlo? Es compartible su idea de que la crítica puede sostenerse desde la existencia de la cultura letrada. Sin establecimiento de criterios normativos, es imposible encontrar un punto desde el que asentar la lucha contra lo existente. A partir de este ángulo de miras, se puede encontrar razón a Sarlo cuando defiende a los expertos y la necesidad de lo normativo, expertos que en gran medida están evaporados en los estudios culturales (Mc Quail).

Pero lo intelectual no se sostiene en el aire, es materialmente producido desde los trabajadores manuales, que garantizan la posibilidad de reproducción de quienes hacen tarea intelectual. Más que eso: en términos lukacsianos (y posteriores de Sohn Rethel), el pensamiento es sólo “forma teórica” de las prácticas sociales, y desde ese punto de vista el horizonte de sentido desde el cual la teoría es posible (y también la literatura, por cierto) se constituye en la práctica social, en un lugar extra-teórico. El pensamiento es deudor -entonces- de quienes no están especializados en producir pensamiento teórico. Y además, para modificar la situación social, hay que partir de las vivencias de los sectores no hegemónicos, de su cotidianeidad y sus costumbres: Es allí donde Benjamin se hace central, y donde los “estudios culturales” tienen mucho que aportar.

de que las identidades nacionales estarían tan fuertemente dañadas, que ya carecerían de densidad propia y de efectos en la acción social (165). 
Son éstas las dos partes escindidas de la verdad, como solía querer la dialéctica en sus tiempos de auge. Los expertos son tan necesarios como la asunción de la cultura popular: es exactamente la forma en que Gramsci se representaba a sí mismo la constitución de hegemonía a partir del folklore y las tradiciones, mediado ello por la imprescindible intervención de los intelectuales. Ni intelectuales sin pueblo, ni pueblo sin intelectuales. $\mathrm{Ni}$ minucia sin totalidad, ni totalidad que aplaste los detalles. Ni elogio unilateral de la cultura de elites, ni subordinación populista a los gustos de las masas. Ni politicismo que ahogue el análisis concreto de la cultura, ni análisis cultural que se desembarace de la política.

¿Es pedir demasiado? Quizás. Pero en el gusto de Benjamin por lo antitético y lo desmesurado tenemos una inspiración egregia para plantearnos la máxima autoexigencia del concepto.

Bibliografía

Adorno, Theodor. Minima moralia. Madrid: Taurus, 1987. y Benjamin, Walter: “Cartas sobre Baudelaire”. Punto de vista 38 (1990): 3-9.

Aguirre, J. “Walter Benjamin: estética y revolución”. Prólogo a Walter Benjamin: Imaginación y sociedad (Iluminaciones I). Madrid: Taurus, 1988. 7-14.

Altamirano, Carlos. "Variaciones sobre Adorno”. Punto de vista 35 (1989): 1-6.

Ballent, A., A. Gorelik y G. Silvestri. "Las metrópolis de Benjamin”. Punto de vista 45 (1993): 19-27.

Benjamin, Walter. Imaginación y sociedad (Iluminaciones I). Madrid: Taurus, 1988.

"La obra de arte en la época de su reproductibilidad técnica”. Discursos interrumpidos. Buenos Aires: Taurus, 1989. 15-58.

“Tesis de filosofía de la historia”. Discursos interrumpidos. Buenos Aires: Taurus, 1989. 175-192.

“El surrealismo (la última instantánea de la inteligencia europea)”. Imaginación y sociedad (Iluminaciones I). Madrid: Taurus, 1988. 41-62.

“Desembalo mi biblioteca”. Punto de vista 26 (1986): 23-27.

Bourdieu, Pierre. Sobre la televisión. Barcelona: Anagrama, 1997.

Colón, Eliseo. "De los medios a las mediaciones o el devenir de la estética y la historia: diálogo entre Walter Benjamin y Jesús Martín-Barbero”. Mapas nocturnos (diálogos con la obra de Jesús Martín-Barbero). VV.AA. Bogotá: Universidad Central-DIUC, 1998. 29-36.

Ferguson, Marjorie y Peter Golding. "Los estudios culturales en tiempos cambiantes: introducción”. Economía política y estudios culturales. Marjorie Ferguson y Peter Golding, eds. Barcelona: Bosch ed., 1998. 15-37.

Follari, Roberto. Modernidad y posmodernidad: una óptica desde América Latina. Buenos Aires: Aique/Rei/IDEAS, 1990.

"Relevo en las ciencias sociales latinoamericanas: estudios culturales, transdisciplinariedad y multidisciplinariedad ”. Dia-logos de la comunicación 65 (2001): 31-36. 
“Posmodernidad y estudios culturales: ¿sinónimos?”. RELEA 10 (2000): 79-101. “Sobre la inexistencia de paradigmas en las ciencias sociales”. Epistemología y sociedad. Rosario: Homo Sapiens, 2000. 111-122.

García Canclini, Néstor. Consumidores y ciudadanos. México: Grijalbo, 1995.

González Requena, Jesús. El discurso televisivo: espectáculo de la posmodernidad. Madrid: Cátedra, 1992.

Herlinghaus, Hermann. "La modernidad ha comenzado a hablarnos donde jamás lo esperábamos. Una nueva epistemología política de la cultura en De los medios a las mediaciones de J.Martín Barbero”. Mapas nocturnos. VV.AA. Bogotá: Universidad Central-DIUC, 1998. 11-27.

Jameson, Fredric. "Conflictos interdisciplinarios en la investigación sobre cultura”. Alteridades 5 (1993): 93-117.

Kuhn, Thomas. La estructura de las revoluciones científicas. México: Fondo de Cultura Económica, 1980.

Landi, Oscar. Devórame otra vez (qué hizo la televisión con la gente, qué hace la gente con la televisión). Buenos Aires: Planeta, 1992.

“Mirando las noticias”. El medio es la TV. A. Vacchieri, comp. Sarandí (Argentina): La Marca, 1992. 78-82.

Lunn, Eugene. Marxismo y modernismo (un estudio histórico de Lukács, Benjamin y Adorno). México: Fondo de Cultura Económica, 1986.

Lyotard, Jean. La posmodernidad explicada a los niños. Barcelona: Gedisa, 1990.

Martín-Barbero, Jesús. De los medios a las mediaciones. Bogotá: Gustavo Gili, 1986. “Mis encuentros con Walter Benjamin”. Constelaciones de la comunicación 1 (2000): 16-23.

"La comunicación en las transformaciones del campo cultural”. Alteridades 5 (1993): 59-68.

Mattelart, Armand y E. Neveu. Introducción a los estudios culturales. Barcelona: Paidós, 2004.

McQuail, Denis. "Se precisa ayuda de una política normativa: con buena disposición y capaz, culturalistas de los medios de comunicación soliciten información, por favor”. Economía política y estudios culturales. Ferguson et al. Barcelona: Bosch, 1998. 95120.

Moraña, Mabel. "Introducción”. Nuevas perspectivas desde/sobre América Latina: el desafío de los estudios culturales. Moraña, comp. Santiago de Chile: Cuarto Propio, 2000. 9-13.

Morley, David. Televisión, audiencias y estudios culturales. Buenos Aires: Amorrortu, 1996.

"Ortodoxias teóricas: el textualismo, el constructivismo y la nueva etnografía en los estudios culturales”. Economía y estudios culturales. Ferguson y Golding, eds. Barcelona: Bosch, 1998. 215-238.

Ortiz, Renato. “Lo actual y la modernidad”. Nueva sociedad 116 (1991): 94-101.

Pérez Rasanz, Ana. Kuhn y el cambio científico. México: Fondo de Cultura Económica, 1999. 
Rojas, M. y S. Sternbach. Entre dos siglos (una lectura psicoanalítica de la posmodernidad). Buenos Aires: Lugar ed., 1994.

Sarlo, Beatriz. "Estética y política: la escena massmediática”. Política y comunicación. H. Schmucler y C. Mata. Buenos Aires: Catálogos, 1992. 50-60.

"El relativismo absoluto o cómo el mercado y la sociología reflexionan sobre estética”. Punto de vista 48 (1994): 27-31.

"Un debate sobre la cultura”. Nueva sociedad 116 (1991): 88-93.

“Lo popular en la historia de la cultura”. Punto de vista 35 (1989): 19-24.

Sartori, Giovanni. Homo videns (la sociedad teledirigida). Madrid: Taurus, 1998.

Schlesinger, Philip. “Comentario sobre Jesús Martín-Barbero”. Comunicação e política 9/1 (2002): 190-195.

Sohn Rethel, Alfred. Trabajo manual y trabajo intelectual. Bogotá: Ed. del Viejo Topo, 1980.

Vattimo, Gianni. El fin de la modernidad. Barcelona: Gedisa, 1987.

Yúdice, George. “Tradiciones comparativas de estudios culturales: América Latina y los Estados Unidos”. Alteridades 5 (1993): 9-20. 